\title{
42 Die Evolution mästet ihre Kinder
}

\author{
(c) Springer-Verlag GmbH Deutschland, ein Teil von Springer Nature 2018 \\ D. Mathias, Fit und gesund von 1 bis Hundert \\ https://doi.org/10.1007/978-3-662-56307-6_42
}

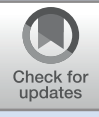

Millionen von Jahren unserer Evolution zeichneten sich durch limitierte Nahrungsressourcen aus. Nahrungsmangel war deshalb stets viel gefährlicher als Nahrungsüberfluss und die optimale Verwertung der Nahrung immer ein Überlebensvorteil. So gesehen sind die XXXL-Menschen von heute die Elite der Evolution, eine Auszeichnung, auf die die meisten von ihnen gerne verzichten würden.

In Deutschland sind ca. $50 \%$ der Menschen in ihrem mittleren Alter übergewichtig (2017), unter den 70-Jährigen sind es gar $65 \%$. Männer sind hiervon mehr betroffen als Frauen. Auch schon ein Zehntel aller Kinder und Jugendlichen ist zu dick mit der tragischen Folge, dass die meisten der übergewichtigen 10- bis 17-Jährigen auch als Erwachsene zu schwer sein werden. Sie tragen ein gesteigertes Risiko u. a. für Blutdruckerhöhungen, die Entwicklung von koronaren Herzkrankheiten, Schlaganfall, Krebs oder für Diabetes bereits im mittleren Erwachsenenalter (Bjorge et al. 2008; Adams et al. 2014; Bairdain et al. 2014; Schlesinger et al. 2015; Twig et al. 2016; - Kap. 47). Das erhöhte Diabetesrisiko aufgrund von Übergewicht im Jugendalter wird auch durch Auswertungen der Nurses' Health Studie II mit den Daten von über 109.000 Teilnehmerinnen bestätigt. Das Risiko normalisierte sich hier aber, wenn die Betroffenen als junge Frauen wieder schlank wurden (Yeung et al. 2010).

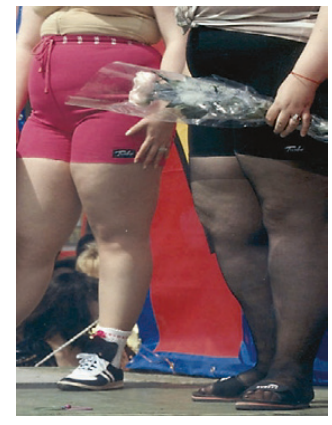

- Abb. 42.1 @ dpa/akg

Ein interessanter Aspekt ergibt sich aus einer kleineren Studie an 13.400 schwedischen Schwesterpaaren (Derraik et al. 2015). Bei diesen waren die älteren Mädchen als Erwachsene schwerer als ihre jüngeren Geschwister, ein Effekt, der bei Jungs schon länger bekannt ist.

Die kausale Erklärung dafür fehlt noch. Eine Hypothese: Die Plazenta funktioniert bei den Erstgeborenen noch nicht optimal, sie lernen deshalb schon im Mutterleib, alle Nährstoffe maximal zu verwerten. Das Problem Übergewicht in der Gesellschaft könnte über diesen Mechanismus weiter zunehmen, weil allgemein der Trend zur 1-Kind-Familie wächst.

Für Übergewicht und Adipositas sind auch genetische Faktoren mitverantwortlich (Wahl et al. 2017). Diese beeinflussen z. B. die Verteilung des Fettgewebes ( $\triangleright$ Kap. 43) und die Regulierung des Hunger- und Sättigungsgefühls. Über 300 Genorte sind bisher bekannt, die mit dem Body-Mass-Index verbunden sind (Heymsfield und Wadden 2017). Das Risiko für ein zu hohes Körpergewicht wird zwar weitgehend durch den Lebensstil der Menschen bestimmt, Gene können aber vernünftige Lebensstilveränderungen erschweren.

Man gräbt sich sein Grab mit den Zähnen (franz. Sprichwort).

Eine das Gewicht vermehrende zu hohe Energieaufnahme erfolgt gelegentlich auch unbeabsichtigt. Verantwortlich ist in diesen eher seltenen Fällen die menschliche Darmflora ( $\triangleright$ Kap. 36). Die hier in Symbiose mit unserem Körper lebenden etwa 50 Billionen Bakterien sind je nach ihrer Zusammensetzung in der Lage, aus unverdaulichen Abfallprodukten unseres Stoffwechsels mehr oder weniger effektiv Energieträger zurückzugewinnen, z. B. Glucose aus der Zellulose. Das geschieht häufig bei einer Fehlbesiedlung des Darms mit einem höheren Anteil an Exemplaren der Gattung Firmicutes und einem verminderten Anteil an Bacteroides. Eine Umstellung der Ernährung kann übrigens schon innerhalb von 24 Stunden die Darmflora verändern (David et al. 2014). 